\title{
Electroinitiated Copolymerization of Styrene and Commercial Divinylbenzene in a Mixed Biphasic System
}

\author{
Prafulla Kumar MAHATA and Bimbadhar NAYAK \\ Department of Chemistry, Indian Institute of Technology, \\ Kharagpur 721302, India
}

(Received February 12, 1987)

\begin{abstract}
The electroinitiated copolymerization of styrene and commercial divinylbenzene has been carried out in an intimately mixed two phase system made of a polar phase consisting of a highly polar solvent, i.e., formamide together with ferric chloride as the added electrolyte, and a non-polar phase formed by the mixture of the two monomers themselves or their solutions in a non-polar solvent like benzene or toluene. The copolymer formed was found to be partially crosslinked and its formation depended on several factors such as the intensity of stirring, concentrations of the electrolyte and the comonomers, strength of the current flow, time of electrolysis and temperature. In split cell experiments, the copolymer is found to be formed in the cathode compartment. A radical mechanism has been proposed to explain the copolymerization reaction.
\end{abstract}

KEY WORDS Electroinitiated Copolymerization / Commercial Divinylbenzene / Split Cell Experiment / Postelectrolysis Polymerization / Solvent Effect / Stirring Effect / Radical Copolymerization /

Electroinitiated polymerization has been studied widely in recent years, but studies related to electroinitiated copolymerization are rather meagre. In earlier communications $^{1,2}$ from this laboratory electroinitiated homo-polymerizations of methyl methacrylate and $N$-vinyl carbazole carried out in two phase reaction media were reported. Similar studies on the electroinitiated copolymerization of styrene with methyl methacrylate ${ }^{3}$ and $\alpha$-methylstyrene with $N$-vinylcarbazole ${ }^{4}$ have been made recently. In all these studies, the biphasic medium consisted of a highly polar phase, i.e., formamide with an added electrolyte, and a non-polar phase that could be either a mixture of bulk monomers themselves or their solutions in a non-polar solvent like benzene or toluene. As explained earlier, ${ }^{2}$ the basic idea for using such two-phase systems is that the more conducting polar phase would allow the passage of sufficient current and chiefly serve as the medium of electrolysis while the nonpolar phase will eventually trap most of the radicals and radical ions found at the electrodes and act as the polymerization medium.

In the present communication, an effort has been made to apply this novel technique to the electroinitiated copolymerization of two liquid monomers namely styrene and commercial divinylbenzene (DVB). Although there have been several reports ${ }^{5-13}$ on the thermal copolymerization of styrene with divinylbenzene, no work on the electroinitiated copolymerization of the above monomers has been reported so far. In the present studies, formamide which has a high dielectric constant $(109.5 \text { at } 298.15 \mathrm{~K})^{14}$ and can be easily deoxygenated ${ }^{15}$ has been used as the solvent for the polar phase. The non-polar phase consisted mostly of a solution of the monomers in either benzene or toluene or was made of the liquid mixtures of the monomers themselves. 
The two phases were almost immiscible with each other. The electrolyte used was ferric chloride. To facilitate the transfer of initiating species, i.e., radicals from the polar phase to the non-plar phase, the two phases were kept in intimate contact with each other by adequate stirring.

\section{EXPERIMENTAL}

\section{Materials}

Styrene (Fluka) was dried over fused calcium chloride $(\mathrm{BDH})$ after the removal of the inhibitor. It was then distilled under reduced pressure and the middle fraction boiling at $353 \mathrm{~K}$ and $755 \mathrm{mmHg}$ pressure was collected and stored at $273 \mathrm{~K}$. Commercial divinylbenzene (Fluka) was freed from the inhibitor in the usual way and then distilled under reduced pressure and the middle fraction boiling at $333 \mathrm{~K}$ and $755 \mathrm{~mm}$ pressure was collected and stored at $273 \mathrm{~K}$. Its composition was almost $50 \% p$ - and $m$ - DVB and $50 \% p$ - and $m$ ethylvinyl benzene by weight together with traces of diethylbenzene. Formamide (BDH, LR) was purified by following the same procedure described by Nayak et al. ${ }^{16}$ To made it free from any dissolved oxygen, the solvent was purified by passing nitrogen through it for 30 minutes. The final product was stored in an air-tight bottle at a temperature below $283.15 \mathrm{~K}$. Anhydrous ferric chloride (Sarabhai M. Chemicals) was dried under vacuum and used without further purification. Methanol (BDH, LR) was used without further purification.

\section{Aparatus and Procedure}

Most of the experiments were carried out in a single compartment cell without separation between the cathode and the anode compartments. For the analysis of individual anode or cathode sections, a split cell was used whose compartments were separated by a sintered glass disk of fine porosity. Each type of cell was fitted with side-tubes for nitrogen inlet and outlet and a side arm for introduction and withdrawal of reaction mixture. The electrodes were made of platinum foils $\left(1 \mathrm{~cm}^{2}\right)$ and were set $1 \mathrm{~cm}$ apart. All experiments were performed at $303.15 \mathrm{~K}$ except as otherwine indicated. The temperature was maintained constant by means of a water bath and the assembly consisting of the cell and the water bath was mounted on a magnetic stirrer to provide adequate stirring to the solution in order to bring the two phases into intimate contact during electrolysis. A teflon coated magnetic bar was used as the stirrer. A variable direct current Power Supply Unit (APLAB, Model 7612) with provision for the measurement of current through the cell as well as voltage applied during electrolysis was used.

The cell was first filled with formamide, containing the added electrolyte which together formed the lower heavier layer $\left(12 \mathrm{~cm}^{3}\right)$ and then either the mixtures of the monomers themselves or their solutions in benzene or toluene were added to the cell to form the upper layer. Nitrogen gas was slowly bubbled through the cell for 30 minutes prior to electrolysis. At the end of the electrolysis, the stirring was discontinued and the copolymer formed at the upper layer was collected by precipitating the same with excess methanol. After subsequent washing of the polymer with methanol and its drying under vacuum, the yields were determined gravimetrically. The polymer obtained was partially soluble in benzene and the soluble part constituted about $60-65 \%$ of the total copolymer. Viscosity measurements of the soluble part of the copolymers were carried out in benzene solution at $25^{\circ} \mathrm{C}$ using an Ostwald viscometer. The viscosity average molecular weight $\left(\bar{M}_{v}\right)$ of the soluble copolymer was determined by using the following relation ${ }^{17}$

$$
[\eta]=37.2 \times 10^{-5} \bar{M}_{v}^{0.7}
$$

\section{RESULTS AND DISCUSSION}

The results of the electroinitiated copolym- 
Table I. Effect of stirring on the electroinitiated copolymerization of styrane and commercial divinylbenzene ${ }^{a}$

\begin{tabular}{clcc}
\hline $\begin{array}{c}\text { Current } \\
\text { passed }\end{array}$ & $\begin{array}{c}\text { Stirred/ } \\
\text { Unstirred }\end{array}$ & $\begin{array}{c}\% \text { of Conversion of } \\
\text { comonomer to } \\
\text { copolymer }\end{array}$ & $\begin{array}{c}R_{\mathrm{p}}(\% \text { of } \\
\text { Conversion/ } \\
\text { hour })\end{array}$ \\
\hline $25 \mathrm{~mA}$ & Stirred & 4.224 & 0.352 \\
$25 \mathrm{~mA}$ & Unstirred & 1.872 & 0.156 \\
$15 \mathrm{~mA}$ & Stirred & 1.335 & 0.111 \\
$15 \mathrm{~mA}$ & Unstirred & Traces & - \\
\hline
\end{tabular}

a Feed composition (mole ratio): formamide-StyreneDVB- $-\mathrm{FeCl}_{3}=30.16: 2.66: 2.12: 1.849 \times 10^{-3}$; temperature, $303.15 \mathrm{~K}$; time of electrolysis, $12 \mathrm{~h}$.

erization studies are summarized in Table I to Table III and Figure 1 to Figure 5. Preliminary experiments showed that the electrocopolymerization occurred only when the current was passed through the cell that contained the electrolyte as well as the monomers. There was no electrocopolymerization in the absence of the electrolyte. The formation of the copolymer was dependent on various factors such as the intensity of stirring, the concentrations of the electrolyte and the monomers, current strength, time of electrolysis and temperature.

Stirring was found to be essential for the electrocopolymarization and as can be seen from Table I, the polymer yield always went up as the intensity of the stirring increased. However, after the two phases got completely mixed there was no further increase in yield due to increased intensity of the stirring. This is probably due to the fact the initiating species formed at the electrodes were shortlived in the unstirred solution on account of recombination, while stirring made them get dispersed in the bulk, thereby making recombination less probable. Other augmenting effects are that stirring promotes diffusion of electroactive species from the bulk to the electrodes and also facilitates the migration of initiating species from the polar to the non-polar phase.

The copolymerization yield was found to depend both on the strength of the current flow as well as the time period of electrolysis.

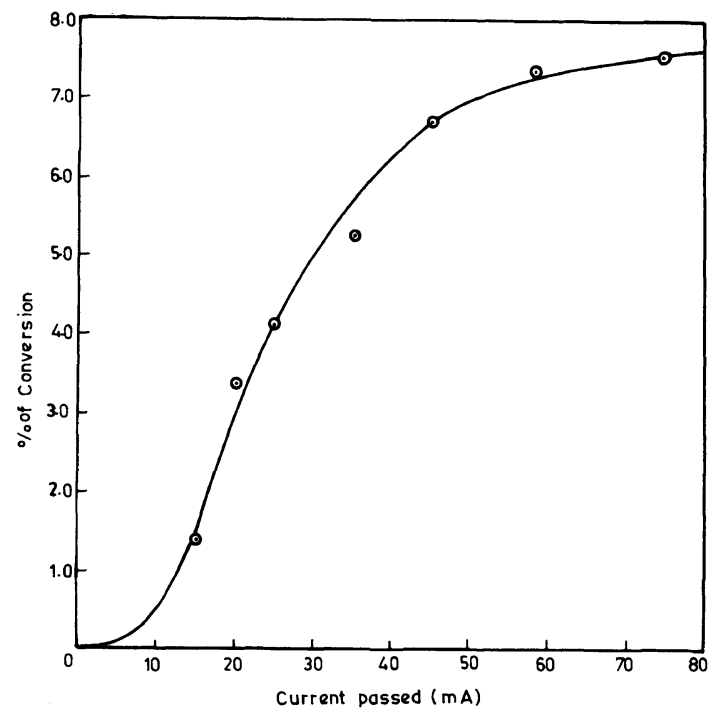

Figure 1. Copolymer formation as a function of current flow. Feed composition (mole ratio): formamidestyrene-DVB-FeCl${ }_{3}=30.16: 2.62: 2.12: 1.849 \times 10^{-3}$; time of electrolysis, $12 \mathrm{~h}$; temperature, $303.15 \mathrm{~K}$.

Figure 1 gives the polymer yield over a fixed period of time (i.e., 12 h) at different current strengths. It was found that the polymer yield at first increased with the current strength but at higher values of the same, it tended to assume a constant value. This may be due to the recombination of initiating species at higher value of the current. A second possibility may be that at higher current strengths, side reactions not leading to polymerization occur.

Figure 2 represents the effect of the time period of electrolysis on the copolymer yield at different current strengths. The yield usually increased with the time of electrolysis, but thereafter, it assumed a constant value. The trend is more or less similar to that observed earlier in other electrocopolymerization studies reported from this laboratory. ${ }^{18}$

The plateau region in Figure 2 is obviously due to the exhaustion of monomers. At the initial stage of electrolysis, the existance of an induction period is quite apparent which may be due to the presence of some electroactive impurities such as moisture. The prolongation 


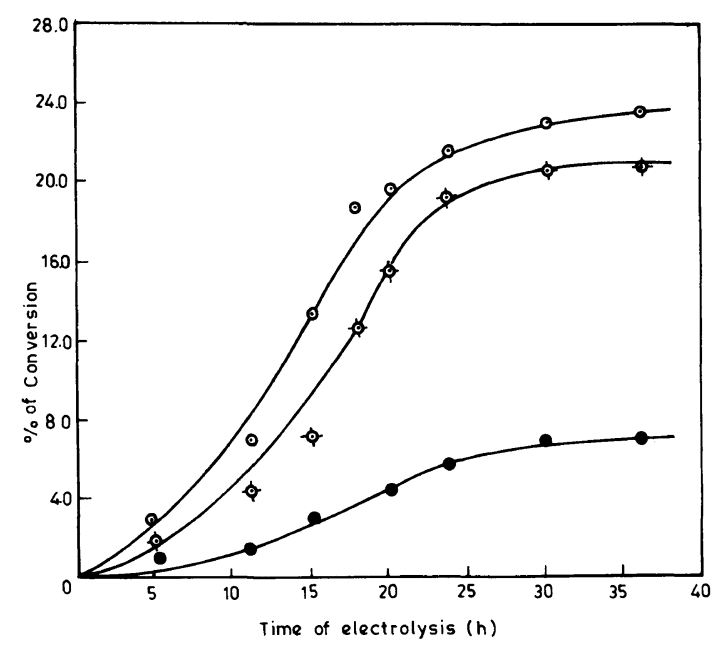

Figure 2. Copolymer formation as a function of time of electrolysis at different current flows. Feed composition (mole ratio): formamide-styrene-DVB$\mathrm{FeCl}_{3}=30.16: 2.62: 2.12: 1.849 \times 10^{-3} ; \quad$ temperature, $303.15 \mathrm{~K}$; (○), $15 \mathrm{~mA}$; (০), $25 \mathrm{~mA}$; (○), $45 \mathrm{~mA}$.

of the induction period at lower current strengths must be due to the greater time required for electrolytic removal of these impurities.

The effect of temperature on the electroinitiated copolymerization process was studied in the temperature range $303.15 \mathrm{~K}$ to $338.15 \mathrm{~K}$. From blank experiments, the extent of thermal copolymerization was checked and found to be negligible. These results in Figure 3 show that the increase of temperature enhances the rate of electrocopolymerization as expected.

The effect of the concentration of electrolyte (i.e., ferric chloride) on the rate of electrocopolymerization was examined at different current strengths and the results are graphically represented in Figure 4. The rate of copolymerization $\left(R_{\mathrm{p}}\right)$ increased initially with the increase in electrolyte concentration, passed through a maximum and then decreased with further increase in electrolyte concentration. However, at lower values of the current (e.g., $25 \mathrm{~mA}$ ), the $R_{\mathrm{p}}$ falls quite sharply after passing through the maximum but at relatively higher

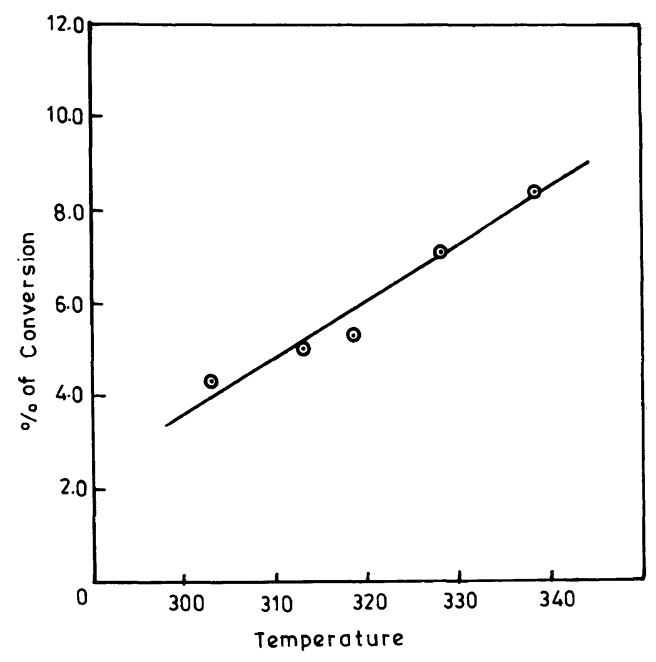

Figure 3. Copolymer formation as a function of temperature. Feed composition (mole ratio): formamidestyrene-DVB-FeCl $3=30.16: 2.62: 2.12: 1.849 \times 10^{-3}$; time of electrolysis, $12 \mathrm{~h}$; current passed, $25 \mathrm{~mA}$.

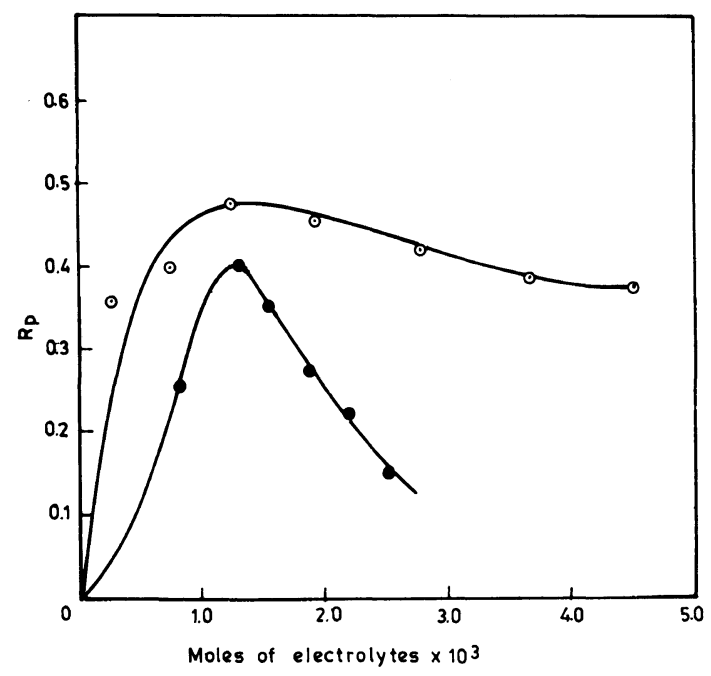

Figure 4. Rate of copolymerization as a function of quantity of electrolyte added and current in the electroinitiated reaction. Feed composition (mole ratio): formamide-styrene-DVB $=30.16: 2.62: 2.12$; time of electrolysis, $6 \mathrm{~h}$; temperature, $303.15 \mathrm{~K}$; (O), $25 \mathrm{~mA}$; (O), $45 \mathrm{~mA}$.

current strengths (e.g., $45 \mathrm{~mA}), R_{\mathrm{p}}$ decreases rather very slowly after reaching the maximum. This could be due to the fact that the increase of concentration of the electrolyte 


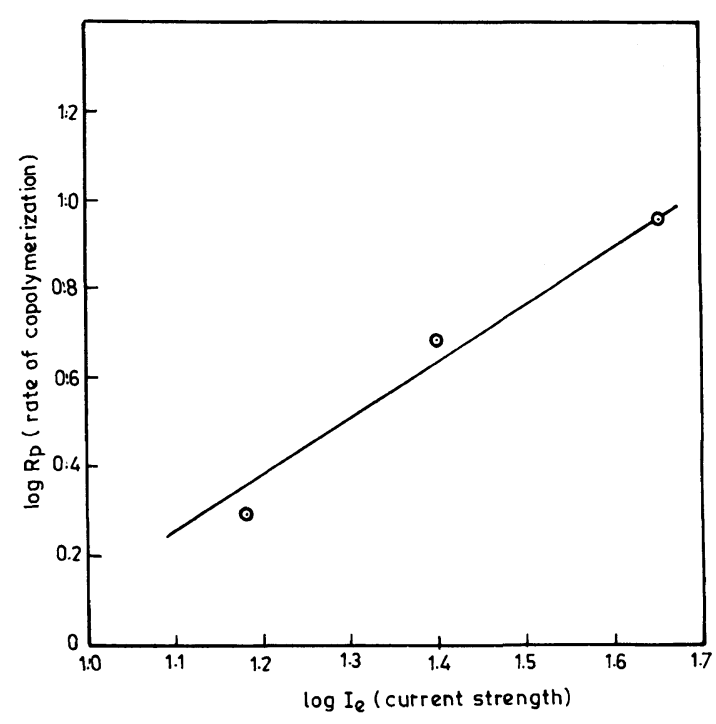

Figure 5. Plot of $\log R_{\mathrm{p}} v s . \log I_{\mathrm{e}}$.

probably leads to the formation of chargetransfer complexes between the monomers and the electrolyte ${ }^{2}$ and thereby affects their reactivity for copolymer formation.

When $\log R_{\mathrm{p}}$ is plotted against the logarithm of the current values in $\mathrm{mA}\left(\log I_{\mathrm{e}}\right)$, corresponding to a $12 \mathrm{~h}$. reaction period, it gives a straight line with a slope of 0.674 , as shown in Figure 5. This clearly shows that at the initial phase of electropolymerization, the rate of polymerization is directly proportional to $2 / 3$ rd power of the current. Although no ready explanation is available for such peculier dependence, the result indicates a complex mechanism for the initiation as well as termination processes of the propagating intermediate.

Post electrolysis polymerization studies showed the presence of living copolymer species in the system. The results are shown in the Table II.

The effects of various polar and non-polar solvents constituting the system on the electroinitiated copolymerization of styrene and commercial divinyl benzene are shown in Table III. It is found that the addition of benzene or toluene to the non-polar phase
Table II. Postelectrolysis polymerization effect on the electroinitiated copolymerization of styrene and divinyl benzene ${ }^{a}$

\begin{tabular}{ccc}
\hline $\begin{array}{c}\text { Time of } \\
\text { current } \\
\text { flow, } \\
\text { in hour }\end{array}$ & $\begin{array}{c}\text { Time allowed for } \\
\text { polymerization in } \\
\text { absence of current } \\
\text { flow, in hour }\end{array}$ & $\begin{array}{c}\% \text { of Conversion } \\
\text { of Comonomer } \\
\text { into the } \\
\text { copolymer }\end{array}$ \\
\hline $6 \mathrm{~h}$ & 0 & 1.52 \\
$6 \mathrm{~h}$ & 12 & 8.32 \\
$12 \mathrm{~h}$ & 0 & 4.22 \\
$12 \mathrm{~h}$ & 12 & 12.13 \\
\hline
\end{tabular}

a Feed composition (mole ratio): formamide-styreneDVB- $\mathrm{FeCl}_{3}=30.16: 2.62: 2.12: 1.849 \times 10^{-3}$; temperature, $303.15 \mathrm{~K}$; current passed, $25 \mathrm{~mA}$.

reduces the rate of copolymerization to some extent. This is quite expected as dilution of the comonomers would affect the rate of propagation steps. The strong inhibiting effect of water is also not unusual and have been observed earlier in many cases of electropolymerization. $^{2}$

The copolymer was characterized by IR spectrocopy. The IR spectrum was taken using the nujol mull technique. The major peaks in the IR spectrum of the copolymer tallies almost with those reported by Bartholin et al. ${ }^{19}$ though the resolution of our spectrum is somewhat poorer. The major peaks are at $1630 \mathrm{~cm}^{-1} \quad(\mathrm{C}=\mathrm{C} \quad$ stretching vibration $)$; $1510 \mathrm{~cm}^{-1}$ (para disubstituted phenyl ring, $v_{\mathrm{C}-\mathrm{C}}$ ); $1440 \mathrm{~cm}^{-1}$ (both mono and disubstituted phenyl rings, $v_{\mathrm{C}-\mathrm{C}}$ ); $1030 \mathrm{~cm}^{-1}$ (mono substituted phenyl ring, $\left.\beta_{\mathrm{C}-\mathrm{H}}\right) ; 900 \mathrm{~cm}^{-1}(\mathrm{di}-$ substituted ring, $\gamma_{\mathrm{C}-\mathrm{H}}$ ); $800 \mathrm{~cm}$ (metadisubstituted aromatic ring, $\left.\gamma_{\mathrm{C}-\mathrm{H}}\right)$.

The X-ray powder photograph of the copolymer showed a hazy pattern characteristic of a amorphous substance.

The copolymer obtained was partially crosslinked as evident from its partial solubility in benzene and also from the loss of fluidity of the reaction mixture (gel formation) during the electrocopolymerization. About 35-40 wt $\%$ of the copolymer was insoluble in benzene and the rest soluble. However, both the soluble 
Table III. The effects of various biphasic systems on the electroinitiated copolymerization of styrene and divinylbenzene as shown in Table II $^{\mathrm{a}}$

\begin{tabular}{lcc}
\hline Biphasic system & $\begin{array}{c}\text { Polar solvent-styrene- } \\
\text { DVB-Non-polar solvent } \\
\text { (mole ratio) }\end{array}$ & $\begin{array}{c}R_{\mathrm{p}}(\% \text { Conversion } \\
\text { of comonomer to } \\
\text { copolymer per hour) }\end{array}$ \\
\hline Formamide-styrene-DVB & $30.16: 2.66: 2.12$ & 0.352 \\
Formamide-styrene-DVB-benzene & $30.16: 2.66: 2.16: 2.84$ & 0.287 \\
Formamide-styrene-DVB-toluene & $30.16: 2.66: 2.16: 2.84$ & 0.281 \\
Water-styrene-DVB & $66.6: 2.66: 2.12$ & nil \\
\hline
\end{tabular}

a Mole of electrolyte per $12 \mathrm{~cm}^{3}$ of the polar phase, $1.849 \times 10^{-3}$; temperature, $303.15 \mathrm{~K}$; time of electrolysis, $12 \mathrm{~h}$.



Figure 6. IR spectra of poly(styrene-co-DVB) (in Nujol) obtained electrochemically in mixed biphasic media.

fractions of the copolymer gave identical IR spectra indicating both the fraction to be of the same copolymer. Viscosity avarage molecular weight $\left(\bar{M}_{v}\right)$ of the soluble copolymer was in the range $(1-2) \times 10^{4}$.

On the basis of the available experimental evidence, it is not possible to throw much light on the mechanism of the copolymerization reaction. However, certain experimental findings indicate the nature of the initiation precess. In split-cell experiments, the locus of copolymerization is found to be the cathode compartment. Again in the presence of hydroquinone, a radical quencher, the electrocopolymerization was found to be completely inhibited which clearly suggests a radical mechanism for the initiation process. On the basis of these and other findings, such as the increase of $R_{\mathrm{p}}$ with stirring and complete inhibition of copolymerization in the presence of water, the following mechanism for initiation process is suggested.

In the presence of ferric chloride, it will be reasonable to assume that $\mathrm{FeCl}_{3}$ forms a charge-transfer complex (I) with styrene. ${ }^{20}$ The complex looses an electron at the anode 
and forms the redical-cation (II)<smiles>CC#CC=C(Cl)Cl</smiles>

(I)<smiles>[CH]C=O</smiles>

(II)
The radical-cation (II) under the influence of stirring quickly migrates to the cathode where the following sequence of reaction take place leading to the eventual formation of the radical (IV)

$$
\begin{aligned}
& 2 \mathrm{HCONH}_{2} \rightleftarrows \mathrm{HCONH}_{3}^{+}+\mathrm{HCON}^{\mathrm{H}} \\
& \mathrm{HCONH}_{3}^{+}+\mathrm{e} \text { (at cathode) } \rightarrow \mathrm{HCONH}_{2}+\dot{\mathrm{H}}(\text { ad. })
\end{aligned}
$$

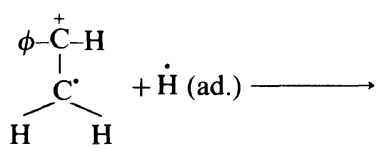

(II)

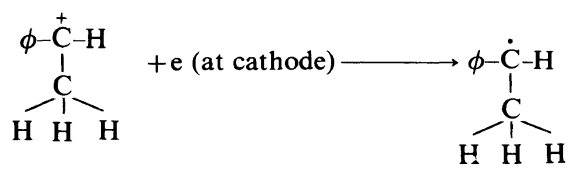

(III)
Radical (IV) then starts the propagation of the copolymerization reaction. Since commercial divinyl benzene does not itself homopolymerize electrochemically in a mixed biphasic medium, whereas styrene does to a small extent, it is therefore reasonable to assume that the former has no role in the initiation process.

In the propagation steps, however, comonomers present in commercial divinylbenzene react with styrene to form the copolymer. It is not clear how the reduction of the cation (III) takes place in the vicinity of the cathode, whether the direct transfer of an electron to the cation occurs from the cathode or indirectly the latter is reduced by $\mathrm{Fe}^{2+}$ produced electrochemically by the cathodic reaction

$$
\mathrm{Fe}^{3+}+\mathrm{e} \longrightarrow \mathrm{Fe}^{2+}
$$

is not known with certainty.

However the later mechanism appears to be more probable and may be outlined as follows:

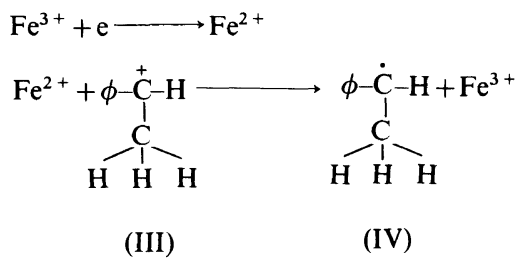

Further evidence for this lies in the fact that during electrocopolymerization, the cathode invariably gets coated with a thin film of metallic iron which can only happen by the cathodic reaction,

$$
\mathrm{Fe}^{2+}+2 \mathrm{e} \longrightarrow \mathrm{Fe}
$$

suggesting the presence of $\mathrm{Fe}^{2+}$ in the reaction medium.

\section{REFERENCES}

1. B. Nayak and R. C. Bhakta, J. Appl. Electrochem., 13, 105 (1983)

2. S. Sanyal, R. C. Bhakta, and B. Nayak, Macromolecules, 18, 1314 (1985).

3. R. C. Bhakta, Ph.D. Thesis, I.I.T., Kharagpur, India (1983).

4. S. Sanyal and B. Nayak, J. Appl. Polym. Sci., in press.

5. R. H. Wiley and Gerald L. Mayberry, J. Polym. Sci., A1, 217 (1963).

6. R. H. Wiley and E. E. Sale., J. Polym. Sci., 46, 423 (1960).

7. D. J. Cram and H. Steinberg, J. Am. Chem. Soc., 73, 569 (1951).

8. H. Nakagawa and Shin Tsunge, Macromolecules, 18, 2068 (1985)

9. D. Thurmond and B. H. Zimm., J. Polym. Sci., 8, 477 (1952).

10. F. Rietsch and D. Froelich, Polymer, 16, 873 (1975).

11. F. Rietsch, A. Brault, and D. Froelich, Polymer, 19, 1043 (1978).

12. F. Rietach, Macromolecules, 11, 47 (1978).

13. F. Rietach and D. Froclich, Eur. Polym. J., 15, 341 (1979). 
14. G. R. Leader, J. Am. Chem. Soc., 73, 856 (1951).

15. G. H. Brown and Hsiao-Shu-Hseiung, Electrochem. Soc., 107, 57 (1960).

16. U. N. Das and B. Nayak, Ind. J. Chem., 8, 679 (1970).

17. I. Ya, Poddubnyi, V. A. Grechanovakii, and M. Z. Mosevitskii, Vysokomol. Soedin, Ser, A., 5, 1042
(1964).

18. N. K. Pattanayak and B. Nayak, Makromol. Chem., 187, 1337 (1986).

19. M. Bertholin, G. Boissier, and J. Dubois, Makromol. Chem., 182, 2075 (1981).

20. V. V. Vasudeva Murty and B. Nayak, Eur. Polym. J., 17, 151 (1981). 